\title{
LAS MOLESTAS PRÓTESIS DEL DR. FREUD. A NOVENTA AÑOS DE EL MALESTAR EN LA CULTURA
}

Gonzalo Percovich

Psicoanalista Miembro de l'École Lacanienne de Psychanalyse Correo electrónico: gonzalopercovich@hotmail.com ORCID: 0000-0002-2456-2572 


\section{Resumen}

Pasados noventa años de la publicación de El malestar en la cultura de Sigmund Freud, con este artículo pretendo explorar qué resonancias actuales posee dicho escrito. En esta apuesta tengo en cuenta tanto la vertiente epocal que se prestó para la reflexión freudiana, como el momento vital del escritor en juego. De la extensa problematización planteada en dicha obra, en este artículo me detengo a reflexionar sobre la noción de felicidad, así como sobre la del hombre como dios-prótesis. Como hipótesis, esbozo la idea de que existiría un hilo de continuidad entre el estado de salud de Freud y el carácter profético que asigna a algunos desarrollos tecnológicos, en plena expansión ya en aquel entonces..

Palabras clave: verdades triviales, felicidad, instante, índice de progreso real (IPR), ciencia ficción, prótesis, ciberespacio, cyborgs.

\section{Dr Freud's Bothersome Prostheses: 90 Years after Civilization and its} Discontents

\section{Abstract}

Over ninety years after the publication of Sigmund Freud's Civilization and its Discontents, this paper attempts to explore its current resonances by elaborating on the epochal aspects that lent themselves to Freudian thinking together with matters then at stake in the author's life. Although Freud's work raises many issues, the paper focuses on the notion of happiness and the idea of mankind as a god-prosthesis. The hypothesis outlined is that it is possible to follow a continuous thread between Freud's health condition and the prophetic character granted to certain technological developments which were already in full expansion at the time.

Keywords: trivial truths; happiness, instant, Real Progress Index (RPI); sciencefiction; prosthesis, cyberspace, cyborgs. 
En algún lugar Michel Foucault escribe que la historia será verdaderamente efectiva en la medida en que, al ser relatada, no posea nada de una estabilidad tranquilizadora, sino que más bien se deje llevar por lo disruptivo, por aquello que sorprende, y que contenga eventualmente algo de una paradoja. Fue de ese modo que leí —en varias de sus biografías- ${ }^{1}$ los avatares de la escritura de El malestar en la cultura. Sigmund Freud se dirige de manera epistolar a aquellos que lo sostienen en sus últimos años de vida, para debatir sobre sus ideas sin nunca dejar de lado el estado espiritual que sostenía su labor intelectual. Así, es conocida la carta que le dirige a Lou Andreas-Salomé ni bien es terminada dicha obra. ${ }^{2}$ Allí expresa:

[mi libro] se ocupa de la civilización, de los sentimientos de culpa, de la felicidad [...] me parece [un libro] superfluo en contraste con obras anteriores, que después de todo surgieron de alguna necesidad interna. ¿Pero qué otra cosa podía hacer? No se puede fumar y jugar a las cartas todo el día; ya no paseo mucho y la mayoría de lo que hay para leer ya no me interesa. Escribí y de esa manera el tiempo pasó bastante agradablemente. He descubierto las verdades más triviales mientras escribía esta obra. (Schur, 1980, p. 613)

1 Especialmente Freud. Una vida de nuestro tiempo, de Peter Gay (1998), El siglo del psicoanálisis, de Emilio Rodrigué (1996), y Sigmund Freud - Lou Andreas Salomé. Correspondencia, compilada por Ernst Pfeiffer (1968).

2 La carta de Freud a Andreas Salomé, del 28 de julio de 1929, se puede leer íntegramente en la obra de Max Schur (1980). 
Una de las obras freudianas que más comentarios ha suscitado es recibida por su autor de esta manera. Una sorprendente paradoja. Su primera edición se agotó rápidamente, como si hubiera brindado respuesta a las incertidumbres propias de aquel entonces: la quiebra de la Bolsa de Valores de Nueva York, que dio comienzo a la Gran Depresión, el ascenso del nazismo y promesas utópicas de toda índole; podríamos decir: grandes acontecimientos históricos. Sin duda lo fueron para los sujetos que habitaron el planeta en aquel entonces, pero al mismo tiempo encuentro que las palabras de Freud dirigidas a su amiga Lou nos devuelven otra mirada de lo allí planteado. ¿Por qué no pensar que es en el momento más trivial que algo de una verdad se revela?, al modo de una distracción, de una divagación circunstancial que se vuelve tan humana como superflua. ¿O acaso no fue al chiste, a la tonta ocurrencia, a la metida de pata, a lo que Freud le dio un valor relevante?

Dirige la mirada a lo más próximo, al cuerpo, a los gustos, a los juegos, allí donde el espíritu discurre de manera inadvertida; a los modos de brindar sosiego en los tiempos de mayor vulnerabilidad. Es una obra escrita entre cigarros y prótesis, entre narcosis y malestares, entre el reposo y la ardua tarea intelectual. Quizás, entonces, sea este el tono en el que su obra merece ser leída. Sin grandes expectativas. Sin hacer de ella una visión del mundo (weltanschauung). Freud siempre intentó desmarcarse de tal pretensión.

Si seguimos el hilo conductor de los primeros capítulos, podemos apreciar que Freud describe de manera elocuente los avatares propios de un sujeto sometido a la vida en sociedad. ¿Es el trabajo, el amor, el sexo, la narcosis, el arte, lo que brinda dicha a los sujetos? Más que pretender dar cuenta de la gran Historia, presenta apenas fragmentos de lo que constituyen tanto los momentos de deleite vital, como los sinsabores de la vida. 


\section{VERDADES TRIVIALES}

Vayamos al texto. La obra es lo suficientemente compleja y amplia, lo que hace imposible abarcarla en su totalidad. Apenas esbozaré algunas reflexiones que convocaron mi interés por sus resonancias con las luces de la ciudad contemporánea. ¿De qué modo Freud nos introduce en los sinsabores de la vida? ¿Cómo el malestar es parte esencial de nuestra condición existencial? Freud no escatima en introducirnos de buenas a primeras en un territorio muy tangible de la vida cotidiana. Expresa: «La vida, como nos es impuesta, resulta gravosa: nos trae hartos dolores, desengaños, tareas insolubles. Para soportarla no podemos prescindir de calmantes» (Freud, 1994, p. 75). Por ser sabido no deja de ser una verdad «trivialmente» contundente. Las condiciones vitales a las que el humano está expuesto son excéntricas. Existe una imposición de exigencias que harán posible o no la prosecución de la vida.

Sin escribirlo explícitamente, desde el comienzo se hace presente la Ananké. ¿Cómo sobrevivir en una sociedad que no es necesariamente generosa a la hora de proveernos de la manutención indispensable? La vida se torna, para Freud, un avatar en que se trata de soportar dichas imposiciones. A primera vista, surgen las condiciones materiales que hacen posible la existencia. Freud está plenamente advertido de ellas, pero no restringe los sinsabores de la vida solamente a aquellas, sino además a las que son efecto de diversos desengaños: el amor, la muerte, el envejecimiento. Su territorio se amplía y en ello cobra profundidad. Ese espesor inaugurado por la diversidad de desengaños en la vida humana lo remite directamente a la pregunta sobre el fin (zweck) de esta. ${ }^{3}$ Freud responde — sin ningún recurso estilístico que pueda atemperar la afirmación— que darle un sentido último a la vida

3 Zweck suele traducirse como 'propósito'. Hablar de 'fin de la vida', como se lee en la versión castellana editada por Amorrortu, puede conducir a un malentendido. 
no es más que una afirmación propia de la arrogancia del hombre. ¿Por qué la vida tendría un sentido/propósito? No la tiene la de los animales. Los animales nacen, crecen, y mueren. ¿Por qué la tendría la de los humanos? Y luego de escribir El porvenir de una ilusión (1994b), vuelve a reafirmar que solo la religión pretende dar una respuesta certera al sentido de la vida.

Entiendo que en dicho planteo se vuelve de una contemporaneidad insoslayable. En aquel entonces Freud quería desmarcar al psicoanálisis de cualquier acercamiento a la religión, del mismo modo que lo había hecho con la medicina. Pero entiendo que es Jacques Lacan quien da la estocada final a dicha afirmación. En 1974, Lacan pondrá en relación el sentido con la religión. Allí donde hay mucho sentido, las puertas de la religión se abren definitivamente, una sentencia que es devuelta a la experiencia analítica. Allí donde un psicoanálisis va excesivamente por las vías del sentido, se vuelve religioso y, así, la vida puede tornarse rápidamente un asunto de propósitos cumplidos.

Freud agrega que si existiese un propósito de la vida al cual los humanos darían su adhesión sería a alcanzar la felicidad y a mantenerla. Sabemos que Freud cambió el título de su obra. Quiso llamarla en un primer momento La desdicha en la cultura (Das Unglück in der Kultur), pero pasó a nombrarla luego El malestar en la cultura (Das Unbehagen in der Kultur), como si malestar (unbehagen) sostuviera una opacidad que el término desdicha (unglück) no poseyera. Este último podría eventualmente abordarse como una simple dicotomía entre la felicidad y la infelicidad. Felicidad se escribe glück en lengua alemana y Freud expresa que dicho término puede ser entendido simplemente como la vivencia de intensos sentimientos de placer (dicha), por lo que malestar — aunque comprenda la dicotomía malestar-bienestar - amplía el concepto del que quiere dar cuenta.

El malestar parece dejar al sujeto en un estado de incomodidad vivencial. El malestar no es recubierto por ningún saber. El malestar insiste. Y de modo paradojal, Freud nos lo advierte con una cita de Goethe: 
«nada es más difícil de soportar que una sucesión de días hermosos» (Freud, 1994c, p. 76), un modo de quebrar cualquier posible dicotomía. En ello está su opacidad.

\section{DE LA FELICIDAD}

En el capítulo II, tanto la definición de felicidad como la escritura realizadas por Freud resultan de una elocuencia remarcable. Expresa:

Felicidad corresponde a la satisfacción más bien repentina de necesidades retenidas, con alto grado de estasis (plötzlichen Befriedigung hoch aufgestauter Bedürfnisse), y por su propia naturaleza sólo es posible como un fenómeno episódico. Si una situación anhelada por el principio del placer perdura, en ningún caso se obtiene más que un sentimiento de ligero bienestar (Behagen); estamos organizados de tal modo que sólo podemos gozar con intensidad el contraste, y muy poco el estado. (Freud, 1994c, p. 76)

¿Quién habla allí?: ¿Freud el analista?, ¿Freud el que se pretende científico, al atenerse a los avatares de las satisfacciones en un aparato psíquico regido por dos principios? ¿o Freud escritor, haciendo uso de su maestría de escritura, siempre próximo a los poetas? La secuencia de sucedáneos a los sufrimientos vitales parece marcar un recorrido del cual él no se excluye: sustancias químicas —inevitables «quitapenas»— hasta provocar una eventual intoxicación (¿la cocaína?, ¿el tabaco?, ¿el alcohol?), el arduo trabajo que signa la secuencia temporal de la vida (al cual dedicó tantas horas de su vida), la sublimación (en su labor intelectual), la belleza (de una Roma que aparece una vez más en las primeras páginas de su escrito) o el amor (un insondable en su larga vida). Entonces, la 
felicidad es definida como un instante, signado por la intensidad, en contraste con otras experiencias. Lo que perdura podrá provocar templanza, pero no felicidad.

La palabra inglesa happiness parece dar cuenta más acabadamente de esta definición. Es un término que se relaciona con lo sucedido, lo contingente, ya que proviene de la palabra del inglés medio hap, que sugiere casualidad, azar. Del mismo modo, lo hace en francés bonheur ‘ja buena hora!'.

Y, bien, Freud concluye que el programa del principio del placer de ser felices es irrealizable. Apenas podemos aspirar a algún modo de cumplimiento deseante y no por ello vivir en una plena miseria, sino que la intensificación de esos momentos puntuales de felicidad daría vuelo a la existencia. Si la felicidad fuera un continuum, seguramente nos deslizaríamos por las vías del tedio vital.

Pero en estos tiempos parece que esa reflexión «trivialmente» freudiana ha sido borrada de forma notoria. Pululan los manuales que prometen felicidad. Así nos lo hace saber Sara Ahmed (2019), quien —explorando las poblaciones que quedan al margen de la norma del mundo globalizado- expresa que los libros de psicología positiva declaran de modo explícito que la felicidad no es más que el logro del éxito económico. De ese modo, la felicidad es medible en términos numéricos al punto de convertirse en un indicador que los propios gobiernos evalúan estadísticamente. La felicidad se escribe en términos de medición y predicción. La autora escribe:

Distintos gobiernos comienzan a introducir la felicidad y el bienestar como activos mensurables y metas específicas de sus programas, complementando el PBI con lo que ha llegado a ser conocido como el índice de progreso real (IPR). La felicidad se ha convertido en un modo más genuino de medir el progreso; la felicidad [...] es el nuevo indicador del desempeño. (Ahmed, 2019, p. 25) 
Este modo de entender la felicidad traduce una forma política concreta que se impone como un ideal incuestionable. El progreso va de la mano del rendimiento laboral y de allí se accede a una felicidad que se promete como permanente. No hace falta que dicho ideal se imponga de modo explícito, sino que este mismo es deslizado silenciosamente por los medios de difusión masiva, dispositivos de control ante cuyo alcance hasta el propio Jeremy Bentham quedaría sorprendido.

Freud sospecha del progreso desde el comienzo de sus primeros escritos. Ya en 1908 realiza un detallado análisis de los alcances de la tecnología y los efectos en la vida de los sujetos (Freud, 1992). Era difícil sustraerse a pensar que la «nerviosidad moderna» de aquel entonces no fuera efecto directo de los avances tecnológicos. Freud no los desconocía, pero estaba advertido de que el alma poseía pliegues mucho más difusos. Para él, la felicidad era algo enteramente subjetivo.

En ese punto Freud no hace ni filosofía ni sociología, sino que se atiene a lo que cada sujeto enuncia como su «condición miserable» en su cotidiano vivir. Freud expresa que cada individuo ha cedido un fragmento de su patrimonio, tanto erótico como vindicativo, en su puesta en común a la cultura. El sujeto se ha visto expuesto a sofocar (unterdrücken) sus pulsiones. ${ }^{4}$ Este postulado se prolonga y complejiza de forma conclusiva en

4 El desarrollo exhaustivo y cada vez más específico de dicho planteo (trieblehre) atraviesa prácticamente toda la obra de Freud. Las resonancias nietzscheanas de su propuesta inicial son notorias. Según Friedrich Nietzsche, la cultura exige la declinación de la fuerza instintiva y en ello consiste la decadencia de la época moderna. Pero, a su vez, es claro que Freud no creía que la respuesta estuviera dada por una simple «liberación sexual». Ya desde 1908 discrepa con Fritz Wittels acerca de tal cuestión y luego lo hará con Wilhelm Reich. Herbert Marcuse (Eros and Civilization..., 1955) en otro tiempo vuelve a instalar ese debate, estimulado en los años sesenta por el Mayo Francés. Pero en ese caso será Foucault quien, por otros motivos, discrepará una vez más con la denominada «liberación sexual». Con respecto a la relación entre Freud y Nietzsche, ver Assoun (1980). 
El malestar en la cultura. Habría un precio a pagar, ${ }^{5}$ una pérdida estaría en juego desde el momento en que los hombres hagan lazo social. De allí la emergencia de una inevitable hostilidad como efecto de esa resignación penosa. De ese modo, la cultura es presentada en su vertiente más costosa. ${ }^{6} \mathrm{El}$ desamparo (hilflosigkeit) humano exige una renuncia ineludible.

\section{¿DE QUÉ PRÓTESIS HABLAMOS?}

Entonces, ¿Freud sostiene una crítica pesimista ${ }^{7}$ de la cultura? Probablemente sí, y ello lo ubicaría como un escritor ${ }^{8}$ que hace una fuerte crítica a la modernidad, pero es también desde su encarnadura subjetiva que enuncia sus afirmaciones. En esos tiempos, Freud transita de médico en médico para paliar la cirugía de su cáncer, en la búsqueda de una prótesis que alivie su malestar. ${ }^{9}$ Su comunicación epistolar revela el doloroso descontento con las prótesis sugeridas. Freud manifiesta síntomas

5 Dicha expresión posee una clara connotación económica. Mi posición enunciativa no deja de estar, aun sin quererlo, signada por la utilidad mercantil. A menos —entiendo— que lo que se reciba por esa paga sea del orden de lo inútil.

6 Con respecto a la singular definición de cultura (kultur) y sus diferencias con respecto a la noción de civilización (zivilisation) y a la de formación cultural (bildung) brindadas por Freud en dicho texto, ver Le Rider (1998).

7 La expresión «crítica pesimista» es utilizada expresamente por Freud (1994c, p. 87) y puede contener resonancias schopenhauerianas, pero no lo desarrollaré ya que ameritaría un análisis que excede a este artículo.

8 Utilizo la nominación escritor y no pensador en el sentido de lo que hizo saber a Lou Andreas Salomé. Aun así, entiendo que Freud no fue un pensador, sino alguien que inauguró un modo de escucha inédito hasta ese entonces.

9 La situación de salud de Freud está extensamente desarrollada por Schur (1980), citado anteriormente, quien fue su médico de cabecera en su último período de vida. Su lectura opera como un contrapunto sugerente a la hora de medir la temperatura de la escritura freudiana en sus últimos años. 
cardíacos y abdominales debido al exceso de nicotina, por lo que permanece abstinente apenas unas semanas. El cigarro lo llama nuevamente. Declara su hartazgo de ser cuidado tan obsesivamente por sus médicos. Quizás ello lo llevó a escribir en su texto: «Y en definitiva, ¿de qué nos vale una larga vida, si ella es fatigosa, huera de alegrías y tan afligente que no podemos sino saludar la muerte como redentora?» (Freud, 1994c, p. 87). No resulta sorprendente, entonces, que dedique un extenso párrafo a la noción de prótesis. Afirma que los hombres perfeccionan sus órganos hasta límites insospechados. Las aptitudes sensoriales tanto como motrices son reforzadas por prótesis de modo tal que el hombre puede llegar a sentirse un dios: dios-prótesis, curiosa afirmación planteada en ese contexto de desvalimiento personal. El conmovedor contraste realza el cuestionamiento freudiano. Y poco más adelante parece erigirse en un profeta sin dios. Expresa:

Épocas futuras traerán consigo nuevos progresos, acaso de magnitud inimaginable, $[\ldots]$ y no harán sino aumentar la semejanza con un dios. Ahora bien, en interés de nuestra indagación no debemos olvidar que el ser humano de nuestros días no se siente feliz en su semejanza con un dios. (Freud, 1994c, p. 90)

Es una profecía que nos retorna en estos tiempos de proliferación maquínica sofisticada. ¿Acaso no hemos devenido verdaderos sujetosprotésicos? ¿No estamos atravesados definitivamente por una suerte de tecnología médica que nos fragmenta en imágenes y cifras que revelan información veraz sobre los avatares de nuestra carne? Nuestro cuerpo, hoy en día, ¿es concebible sin alguna prótesis que nos prometa una eventual prolongación de la vida? Da la impresión de que las prótesis aún pretenden conservar la Gestalt especular que nos muestra como humanos. 
Pero ni tanto. La clínica médica: ¿comenzó a inclinarse ${ }^{10}$ mucho más hacia el avance tecnológico que hacia el cuerpo sufriente tendido en la camilla? Los hospitales: ¿se han transformado en enormes dispositivos tecnológicos? El tacto, el olfato, el ojo clínico: ¿quedó subsumido a una enorme máquina de condiciones panópticas?

En una entrevista realizada a Lacan en $1974,{ }^{11}$ este afirma que, según él, el psicoanálisis es Freud y que, si uno quiere hacer psicoanálisis, es necesario referirse a Freud, a sus términos, a sus definiciones, leídos e interpretados en su sentido literal. Seguidamente, la entrevistadora le pregunta qué es lo que no anda en el hombre hoy en día. Lacan (1974) responde: "Hay una gran fatiga de vivir como resultado de la carrera hacia el progreso. Se espera del psicoanálisis que descubra hasta dónde se puede llegar arrastrando esa fatiga, ese malestar de la vida» (s. p.). Y algo más adelante lo interroga sobre la relación entre el psicoanálisis y la ciencia, a lo cual Lacan (1974) responde:

Para mí la única ciencia verdadera seria a seguir es la ciencia-ficción. [...] La otra, la que es oficial, que tiene sus altares en los laboratorios, avanza a tientas [...]. En fin, diría yo, ¿y si fuera demasiado tarde? Recién ahora, cuando ellos [los científicos] están destruyendo el universo, se les ocurre preguntarse si por casualidad esto no podría ser peligroso. Y ¿si todo estallara?, ¿si las bacterias tan amorosamente criadas en los blancos laboratorios se transmutaran en enemigos mortales?, ¿si el mundo fuera arrollado por una horda de esas bacterias con toda la mierda que lo habita, comenzando por los científicos de los laboratorios? A las tres posiciones imposibles de Freud, gobernar, educar,

10 Del griego klinein 'inclinarse'.

11 Esta entrevista a Lacan fue realizada el 21 de noviembre de 1974 por Emilia Granzotto y se publicó en la revista italiana Panorama con el nombre «Freud per sempre». 
psicoanalizar, yo agregaría una cuarta: la ciencia. Salvo que ellos, los científicos, no saben que están en una posición insostenible [...] pero no soy para nada pesimista. (s. p.)

\section{DE LAS PRÓTESIS A LOS CYBORGS}

Es con el crecimiento exponencial de la cibernética que el hombremáquina u hombre-protésico advino una suerte de cyborg, ${ }^{12}$ entendido este como una criatura compuesta de elementos orgánicos y dispositivos cibernéticos, generalmente con la intención de mejorar las capacidades de la parte orgánica mediante el uso de la tecnología..$^{13}$ Pero antes de pasar a los cyborgs vayamos a los cibernéticos. Según el autodenominado grupo Tiqqun (2015),

El discurso cibernético comienza por mandar al estante de los falsos problemas, las controversias del siglo xIx que oponían las visiones mecanicistas a las visiones vitalistas $\mathrm{u}$ organicistas del mundo. Postula una analogía entre el funcionamiento de los organismos vivientes y el de las máquinas, asimilados bajo la noción de 'sistema'. (p. 79)

Los humanos hemos quedado expuestos a una suerte de naturaleza de otro orden. La tensión ya no se plantea entre máquina y ser viviente, sino en la enigmática conjunción de ambos.

Tiqqun (2015) no deja de señalar que este hecho es una ficción y al mismo tiempo un hecho político de gran importancia. Es el advenimiento de otra época tecnológica que interroga una vez más la relación entre

12 Cyborg es en inglés el acrónimo de cyber 'cibernético' y org 'organismo'.

13 El término fue acuñado por Manfred E. Clynes y Nathan S. Kline en 1960. 
naturaleza y cultura. Las fronteras entre ciencia ficción y realidad social se desdibujan ${ }^{14}$ y constituyen un asunto de política-ficción.

El término griego kubernesis significa 'pilotear una nave'. La navegación por internet exige del sujeto el aprendizaje de una técnica para acceder a la información requerida, debe saber pilotear —entender cómo funcionan los dispositivos aporta un nuevo poder-, pero al mismo tiempo el individuo es captado por una compleja red donde su vida social es compartida y acumulada de tal modo que la cibernética se ha transformado en una nueva tecnología de gobierno. Tiqqun (2015) lo describe de manera elocuente así:

creemos que nuestros 'datos personales' nos pertenecen como nuestro coche y nuestros zapatos y que al permitir que Google, Facebook Apple, Amazon o a la policía tengan acceso a ellos estamos ejerciendo inocentemente 'nuestra libertad individual', sin darnos cuenta de que hacerlo tiene efectos inmediatos. (p. 45)

Los sujetos pueden pensar que son libres, pero dicha libertad va junto a la vigilancia y el control. ¿Una cultura virtual que consiste en la conexión permanente? ¿Sería pues el advenimiento de una nueva política de los sujetos? De algún modo, todos nos hemos convertido en cibernéticos en la medida en que el planeta advino una gran máquina abstracta. Los cibernéticos comprenderíamos, pues, una constelación difusa, inmersos en una galaxia en plena expansión, que no se homologaría a la vieja noción de masa. En El malestar en la cultura Freud (1994c) advierte acerca de la «miseria psicológica de la masa», entendiendo a esta última como la identificación recíproca entre los participantes que provoca un estado

14 Al respecto, la novela de ciencia ficción Neuromancer, de William Gibson Neuromante (1984), es uno de los ejemplos más claros que indaga esta intersección entre la realidad social y la ciencia ficción. Fue considerada una de las primeras novelas cyberpunk. 
de inercia comportamental. En aquel entonces, ese fenómeno cobraba múltiples formas: desde la unificación de los individuos en torno a un líder, hasta la promesa de felicidad brindada por el capitalismo industrial en plena expansión (sociedad de masas). Pero en el caso del mundo cibernético, más que hablar de masa, podríamos hablar de multitudes conectadas, ${ }^{15}$ de flujos de intensidades que se reúnen y se apartan de modo puntual y que, aun bajo vigilancia, pueden producir fenómenos insospechados de producción cultural. Basta que se instale una red de control —en este caso, global— para que la diversidad de tribus que circulan por dicha red encuentre alternativas de resistencia. Al mismo tiempo que la cultura se globaliza, también se diversifica.

\section{¿UNA ERÓTICA CYBORG?}

Los cyborgs parecen ya ser un hecho ineludible. Habitan nuestra geografía terrestre sin provocarnos gran sorpresa. Muchas veces, porque desconocemos el modo en que fueron conquistando territorios; otras, porque hacemos uso de ellos y nos proveen de un confort ya adquirido. Según Donna Haraway (2018), en algún sentido todos tenemos algo de cyborgs. Ella expresa que ya a fines del siglo xx nos constituimos en quimeras, híbridos teorizados y fabricados, y que lo que vayan a hacer los cyborgs es una interrogación radical.

En 1919, sin hablar aún del hombre como dios-prótesis y en otro contexto, Freud (1994a) hizo propias las palabras de un tal E. Jentsch, quien destacó que, en la literatura fantástica de aquella época, uno de los

15 Entiendo la diferencia entre masa y multitud a partir de los desarrollos de Michael Hardt y Antonio Negri (2004). La masa es un agrupamiento que se acercaría a las turbas, donde las diferencias individuales se borran fácilmente; en cambio, la multitud sería un conjunto de singularidades plurales, sin una cabeza política, sino como un agente político móvil. 
eventos que producían un singular sentimiento de espanto era la duda acerca de si un personaje animado era o no viviente. ¿Cómo distinguir un autómata de un ser vivo?

Así, Freud se remite al personaje Olimpia —una suerte de muñeca móvil— del cuento de E. T. A. Hoffmann, para describir el sentimiento de lo siniestro (das unheimliche). Nathaniel cree haberse enamorado de Olimpia, hija de Spalanzani, quien lo cautiva por su belleza enigmáticamente silenciosa e inmóvil. Una muñeca que es una verdadera máquina de relojería, la cual posee unos ojos hipnotizadores. Nathaniel se enamora perdidamente de ella hasta enloquecer. ¿Un Eros maquínico? ¿Un Eros que es puro efecto de una inquietante extrañeza?

Si fuera el caso, Freud ya ubicaba entonces, en ese tiempo de su escritura, al amor en las antípodas de un Bien soberano. El amor se nutre de las turbias aguas del desconocimiento. Lo que causa espanto atrae. Estas ideas no están lejos de lo que años más tarde escribirá en El malestar en la cultura acerca de la ingenuidad de pensar el amor en términos benevolentes. Y si bien Freud está advertido de que ni un dios-prótesis ni el amor prometen una felicidad eterna, en estos tiempos que corren, ¿hablaría de un Eros cyborg? Seguramente, apenas haría un comentario trivial, disfrutando de su último cigarro...

\section{$\S$}

\section{REFERENCIAS BIBLIOGRÁFICAS}

Assoun, P. L. (1980). Freud et Nietzsche. PUF.

Ahmed, S. (2019). La promesa de felicidad. Una critica cultural al imperativo de la alegría. Caja Negra. 
FREUD, S. (1992). La moral sexual «cultural» y la nerviosidad moderna (1908). En Obras completas (vol. IX, pp. 159-182). Amorrortu.

FREUd, S. (1994a). Lo ominoso (1919). En Obras completas (vol. xviI, pp. 215-252). Amorrortu.

FREUD, S.. (1994b). El porvenir de una ilusión (1927). En Obras completas (vol. xxI, pp. 3-55). Amorrortu.

FREUD, S. (1994c). El malestar en la cultura (1930). En Obras completas (vol. xxI, pp. 57-140). Amorrortu.

GaY, P. (1998). Freud. Una vida de nuestro tiempo (trad. J. Piatigorsky). Paidós.

Gibson, W. (1996). Neuromante (trads. J. Arconada y J. Ferreira). Minotauro. HaraWay, D. (2018). Manifiesto para cyborgs. Ciencia, tecnología y feminismo socialista a finales del siglo $x x$ (trad. S. Bras Harriot). Letra Sudaca.

Hardt, M. y Negri, A. (2004). Multitud. Guerra y democracia en la era del Imperio (trad. J. A. Bravo). Debate.

LACAN, J. (1974). Freud per sempre [entrevista realizada el 21 de noviembre de 1974 por Emilia Granzotto]. Revista Panorama. https://psicoanalisislacaniano.com/

Le Rider, J. (1998). Cultiver le malaise ou civiliser la culture? En J. Le Rider, M. Plon, G. Raulet y H. Rey-Flaud, Autour du Malaise dans la culture de Freud (pp. 79-118). PUF.

Marcuse, H. (1955). Eros and Civilization. A Philosophical Inquiry into Freud. Beacon Press.

Pfeiffer, E. (comp.) (1968). Sigmund Freud - Andreas Salomé, Lou. Correspondencia. Siglo XXI.

RodriguÉ, E. (1996). El siglo del psicoanálisis. Sudamericana.

Schur, M. (1980). Sigmund Freud. Enfermedad y muerte en su vida y en su obra (vol. 2). Paidós.

Tiquun (2015). La hipótesis cibernética. "A propósito de Tiqqun" de Giorgo Agamben. "Fuck off Google" del Comité Invisible. Acuarela y A. Machado. 
